\title{
Single-port minimally invasive esophagectomy
}

\author{
Jen-Hao Chuang, Shun-Mao Yang, Pei-Wen Yang, Pei-Ming Huang, Jang-Ming Lee \\ Department of Surgery, National Taiwan University Hospital and National Taiwan University College of Medicine, Taipei, Taiwan \\ Correspondence to: Dr. Jang-Ming Lee. 7, Chung-Shan South Road, Taipei, Taiwan. Email: ntuhlee@yahoo.com.
}

\begin{abstract}
With the growing evidence of clinical benefit of minimally invasive esophagectomy (MIE) combined video-assisted thoracoscopic surgery (VATS) and laparoscopy procedures, we describe how these procedures can be performed with single-incision both in the abdominal and thoracic phases. Clinical observation of the midterm results has demonstrated its feasibility and benefit of relieving postoperative pain. However, the long-term impact on the survival of the patients requires to be evaluated in the future.
\end{abstract}

Keywords: Esophageal cancer; minimally invasive esophagectomy (MIE); single-incision minimally invasive esophagectomy (SIMIE)

Received: 31 May 2018; Accepted: 29 October 2018; Published: 06 December 2018.

doi: 10.21037 /jovs.2018.10.23

View this article at: http://dx.doi.org/10.21037/jovs.2018.10.23

\section{Introduction}

As minimally invasive esophagectomy (MIE) combining laparoscopic and thoracoscopic procedures has gradually accepted as a feasible approach in treating esophageal cancer (1-9), we describe our experience using a singleincision thoracoscopic and laparoscopic approach for treating esophageal cancer which has been published for the first time in literature before (10).

\section{Patient selection}

The selection criteria for SIMIE (single-incision MIE) included: (I) no evidence of tumor invasion to the adjacent organ in imaging studies (excluding T4 disease) or no previous history of abdominal or thoracic surgery; (II) onelung ventilation can be tolerated during surgery. Informed consent has been obtained from the patients.

\section{Operative procedures}

\section{Esophagectomy and mediastinal lymph node dissection}

With the patient in a lateral position, a $3-4 \mathrm{~cm}$ incision is created through the sixth or seventh intercostal space on the mid-axillary line. The angle between the axes of the oesophagus and surgical instrumentation must be kept in excess of $30^{\circ}$ to facilitate a smooth dissection for the area near the right recurrent laryngeal nerve area.

\section{Surgical exposure under single-portal thoracoscopy}

When patient in lateral decubitus position, the posterior mediastinum and its underlying esophagus would be covered by posterior aspect of right upper lobe and right lower lobe, which makes them unable to be approached directly, especially when lung collapse is not optimal. To help the exposure of the surgical fields, several retention stitches over the boarder of esophagus and fixed extracorporally to prevent to hindrance of lung to the surgical field (10). The azygous vein is at first divided followed by mobilization and looping of the esophagus. When doing Ivor-Lewis procedure, distal esophagus end can be grasped and pulled upward to enhance mobilization of the esophagus after division of the gastric tube, and looping of the esophagus is not recommended.

\section{Mediastinal esophageal mobilization and lymphadenectomy (Figures 1,2)}

Esophageal mobilization and lymphadenectomy along the esophagus, para-tracheal and bilateral recurrent laryngeal nerves is performed. The vagus nerve is identified before dissection of the para-tracheal and right recurrent nerve region to avoid its injury as well as help preservation of 


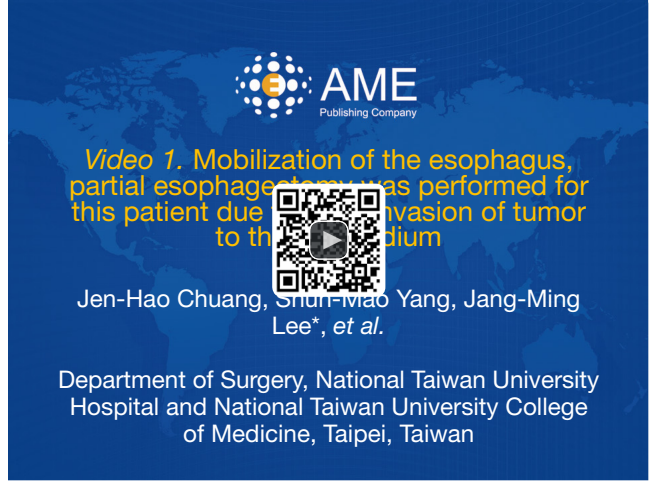

Figure 1 Mobilization of the esophagus, partial esophagectomy was performed for this patient due to focal invasion of tumor to the pericardium (11).

Available online: http://www.asvide.com/article/view/28709

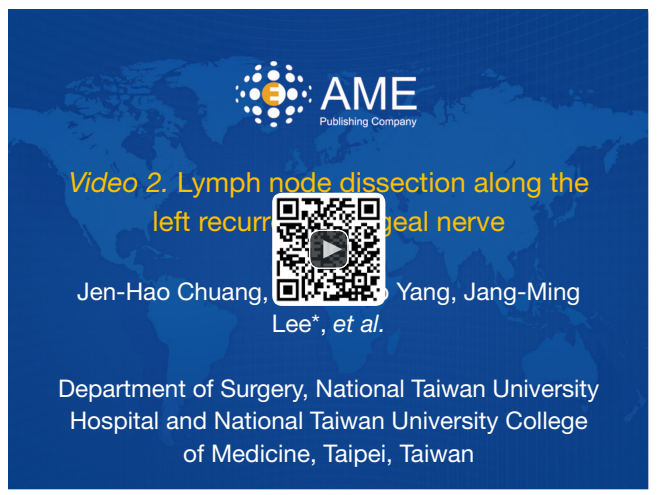

Figure 2 Lymph node dissection along the left recurrent laryngeal nerve (12). Tenting of mobilized esophagus is performed for a better exposure of the surgical field.

Available online: http://www.asvide.com/article/view/28710

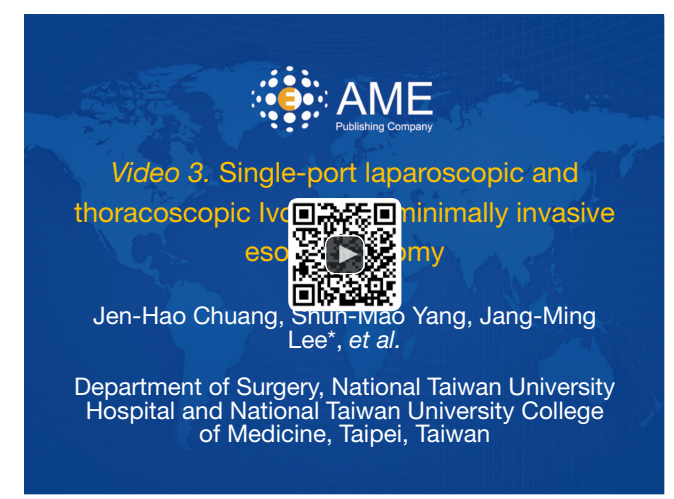

Figure 3 Single-port laparoscopic and thoracoscopic Ivor-Lewis minimally invasive esophagectomy (13).

Available online: http://www.asvide.com/article/view/28711 right recurrent laryngeal nerve during the procedure of lymph node dissection. Figure 1 demonstrates the process of esophageal mobilization and partial pericardiectomy due to focal tumor invasion after neoadjuvant chemoradiation. Figure 2 demonstrates the procedure of lymph node dissection along the left recurrent laryngeal nerve with aids of tenting of mobilized esophagus for a better exposure of the surgical field.

\section{Gastric mobilization under single-portal laparoscopy (Figure 3)}

During the laparoscopic procedure, a $3-\mathrm{cm}$ incision is made along the umbilicus and retracted with a surgical woundprotector (GelPoint, Applied Medical, CA, USA), which allows the use of two or three surgical instrument and a 5or $10-\mathrm{mm}$ camera in the procedure (10). A self-retaining fixing stitch passing through the diaphragmatic hiatus and tightened extra-corporally is used for retraction of liver (10). The stomach is mobilized via opening the greater and lesser sac along the greater and lesser curvature and dividing short and left gastric arteries are divided with ultrasonic or bipolar scissors. Lymph nodes in the hiatus, lesser curvature, left gastric and celiac trifurcation are dissected after gastric mobilization. A feeding jejunostomy was performed on the jejunum $40 \mathrm{~cm}$ from the Treitz ligament unless the patient had already had the procedure done prior to CCRT. The jejunum was fixed onto the abdominal wall through two stitches of preionization through strait needle and extracorporeal fixation. A 12\# Fr central venous catheter was placed into the lumen of jejunum and completed with two more stitches of preionization. The detail procedure of laparoscopic jejunostomy was done as our previous published paper (14).

\section{Completion with esophagogastrostomy}

\section{Tri-incision esophagectomy}

Followed by thoracic procedure, the patients were shifted to supine or lithotomy position for both abdominal and cervical procedures. The gastric conduit and cervical esophagus were anastomosed over left cervical area through either posterior mediastinal or substernal route.

\section{Ivor-Lewis esophagectomy (Figure 3)}

For the Ivor-Lewis approach, a DST OrVil circular staple with the anvil introduced transorally is used to perform the 
intrathoracic esophagogastrostomy. After opening the tip of gastric tube, two retaining stitches were made on the edge of tip opening to allow the introduction of the PCEEA applier. After completion of the esophagogastrostomy by approximation of both end of PCEEA, the defect of gastric tube was closed with linear stapler. The sharp end of the staple lines on the stomach and esophagus was reinforced and inverted into the esophageal and gastric lumen to make the stapling surface smooth to avoid injuring to the adjacent organ by the exposed stapling metals. Figure 3 demonstrate the procedure of Ivor-Lewis procedure from the abdomen to the chest. The procedure of tri-incision procedure, including the esophageal as well as gastric mobilization and lymphadenectomy is similar to that of Ivor-Lewis only with different sequence from the chest to the abdomen.

\section{Discussion}

According to our preliminary experience, MIE can be effectively performed with single-port approach either in the Ivor-Lewis or tri-incision surgery. With the aids of long and thin surgical instrumentation and stich-aid tenting of the adjacent organs, the surgical procedures can be performed as that done in the multi-incision surgery. As our previously published results, the perioperative and oncological outcome of SIMIE was similar as compared to that done by multiport-MIE (10). The pain scores on the $7^{\text {th }}$ day after surgery were significantly lower in the SIMIE group than in the MIMIE group. Whether these findings can be translated into a better quality of life or patient satisfaction requires to be evaluated in the future. Especially, the clinical value for the long-term outcome after surgery for esophageal cancer remained to be clarified with the accumulation of more clinical experience and more well conducted clinical studies.

\section{Acknowledgments}

Funding: This study was supported by the National Taiwan University Hospital (NTUH.106-S3439 and NTUH.107-S3867), Ministry of Science and Technology (MOST 106-2320-B-002-029-MY3 and MOST 107-2314-B-002-248-MY3), and Society of the Chest Care of Taiwan.

\section{Footnote}

Provenance and Peer Review: This article was commissioned by the Guest Editor (Jose Luis Danguilan) for the series "Dedicated to the 6th Asian Single-port VATS Symposium 2018" published in fournal of Visualized Surgery. The article has undergone external peer review.

Conflicts of Interest: All authors have completed the ICMJE uniform disclosure form (available at http://dx.doi. org/10.21037/jovs.2018.10.23). The series "Dedicated to the 6th Asian Single-port VATS Symposium 2018" was commissioned by the editorial office without any funding or sponsorship. The authors have no other conflicts of interest to declare.

Ethical Statement: The authors are accountable for all aspects of the work in ensuring that questions related to the accuracy or integrity of any part of the work are appropriately investigated and resolved. All procedures performed in studies involving human participants were in accordance with the ethical standards of the institutional and/or national research committee(s) and with the Helsinki Declaration (as revised in 2013). Written informed consent was obtained from the patient for publication of this manuscript and any accompanying images.

Open Access Statement: This is an Open Access article distributed in accordance with the Creative Commons Attribution-NonCommercial-NoDerivs 4.0 International License (CC BY-NC-ND 4.0), which permits the noncommercial replication and distribution of the article with the strict proviso that no changes or edits are made and the original work is properly cited (including links to both the formal publication through the relevant DOI and the license). See: https://creativecommons.org/licenses/by-nc-nd/4.0/.

\section{References}

1. Luketich JD, Alvelo-Rivera M, Buenaventura PO, et al. Minimally invasive esophagectomy: outcomes in 222 patients. Ann Surg 2003;238:486-94; discussion 494-5.

2. Smithers BM, Gotley DC, Martin I, et al. Comparison of the outcomes between open and minimally invasive esophagectomy. Ann Surg 2007;245:232-40.

3. Palanivelu C, Prakash A, Senthilkumar R, et al. Minimally invasive esophagectomy: thoracoscopic mobilization of the esophagus and mediastinal lymphadenectomy in prone position--experience of 130 patients. J Am Coll Surg 2006;203:7-16.

4. Sutton CD, White SA, Marshall LJ, et al. Endoscopic- 
assisted intrathoracic oesophagogastrostomy without thoracotomy for tumours of the lower oesophagus and cardia. Eur J Surg Oncol 2002;28:46-8.

5. Senkowski CK, Adams MT, Beck AN, et al. Minimally invasive esophagectomy: early experience and outcomes. Am Surg 2006;72:677-83; discussion 683.

6. Nguyen NT, Roberts P, Follette DM, et al. Thoracoscopic and laparoscopic esophagectomy for benign and malignant disease: lessons learned from 46 consecutive procedures. J Am Coll Surg 2003;197:902-13.

7. Nguyen NT, Schauer P, Luketich JD. Minimally invasive esophagectomy for Barrett's esophagus with high-grade dysplasia. Surgery 2000;127:284-90.

8. Martin DJ, Bessell JR, Chew A, et al. Thoracoscopic and laparoscopic esophagectomy: initial experience and outcomes. Surg Endosc 2005;19:1597-601.

9. Leibman S, Smithers BM, Gotley DC, et al. Minimally invasive esophagectomy: short- and long-term outcomes. Surg Endosc 2006;20:428-33.

10. Lee JM, Yang SM, Yang PW, et al. Single-incision laparo-

doi: 10.21037 /jovs.2018.10.23

Cite this article as: Chuang JH, Yang SM, Yang PW, Huang PM, Lee JM. Single-port minimally invasive esophagectomy. J Vis Surg 2018;4:244. thoracoscopic minimally invasive oesophagectomy to treat oesophageal cancer. Eur J Cardiothorac Surg 2016;49 Suppl 1:i59-63.

11. Chuang JH, Yang SM, Yang PW, et al. Mobilization of the esophagus, partial esophagectomy was performed for this patient due to focal invasion of tumor to the pericardium. Asvide 2018;5:897. Available online: http://www.asvide. com/article/view/28709

12. Chuang JH, Yang SM, Yang PW, et al. Lymph node dissection along the left recurrent laryngeal nerve. Asvide 2018;5:898. Available online: http://www.asvide.com/ article/view/28710

13. Chuang JH, Yang SM, Yang PW, et al. Single-port laparoscopic and thoracoscopic Ivor-Lewis minimally invasive esophagectomy. Asvide 2018;5:899. Available online: http://www.asvide.com/article/view/28711

14. Yang SM, Hsiao WL, Lin JH, et al. Laparoscopic percutaneous jejunostomy with intracorporeal $\mathrm{V}$-Loc jejunopexy in esophageal cancer. Surg Endosc 2017;31:2678-86. 